\title{
Early Conciliation launches in Northern Ireland
}

Following a change in employment law, the Labour Relations Agency will provide a new Early Conciliation service to employees, employers, and their representatives.

The service, which came into effect on 27 January 2020, brings Northern Ireland in line with the rest of the UK. As a result, anyone who wishes to lodge a claim with the Industrial or Fair Employment Tribunal must first notify the Agency and discuss the option of Early Conciliation. Potential claimants will not be able to proceed to tribunal without at least considering this option.

This marks a significant change from the current situation, whereby claims can be lodged with the tribunal and the Agency then has a duty to make contact with the parties to offer conciliation. Tribunal claims usually have to be presented within three or six months of the alleged incident or behaviour, depending on the type of claim. However, when an individual makes an Early Conciliation notification the clock will stop for a period up to one calendar month during which conciliation can take place. The Conciliation Officer will also have the power to extend for a further 14 days providing there is a reasonable prospect of an agreement and that both parties agree.

\section{'The service, which came into effect on 27 January 2020, brings Northern Ireland in line with the rest of the UK.'}

Once an Early Conciliation notification is logged the prospective claimant (or their representative) will then be contacted by one of the Agency's Conciliation Officers, usually within five working days. S/he will explain how conciliation works and, with the individual's consent, will contact the other party to ask if there's a willingness to try Early Conciliation. If both parties agree, the Conciliation Officer will try to help find a solution they both find acceptable and the settlement will be legally binding. If parties cannot agree a settlement, the

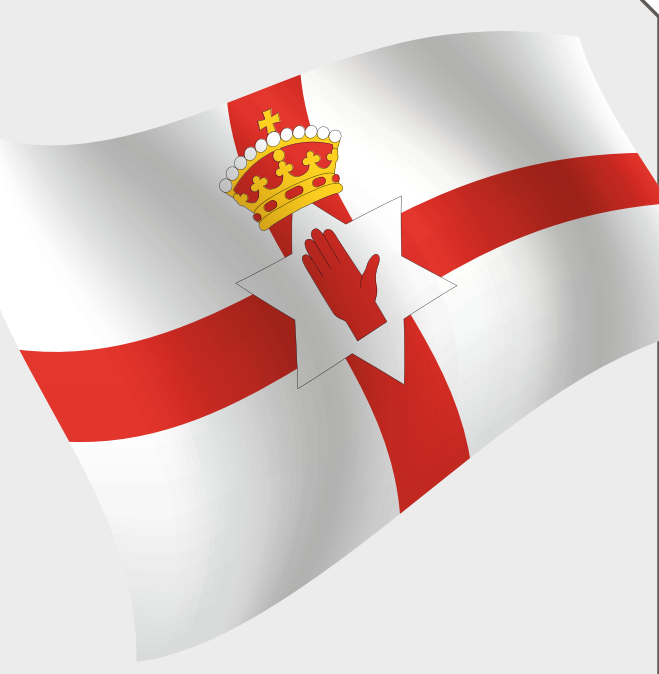

Agency will issue an Early Conciliation certificate which individuals will need if they decide to proceed to tribunal.

BDA members who are contacted by the Agency should seek advice immediately as well as contacting their legal expenses insurers (if they hold such cover). You can contact the BDA practice support team on 02075634563 . The Labour Relations Agency can be contacted on 03300552220 or visit www.lra.org.uk.

\section{Member notice: register for online Performer List service}

In December, Primary Care Support England (PCSE) launched a new online Performers List service and sent a verification email to dentists explaining

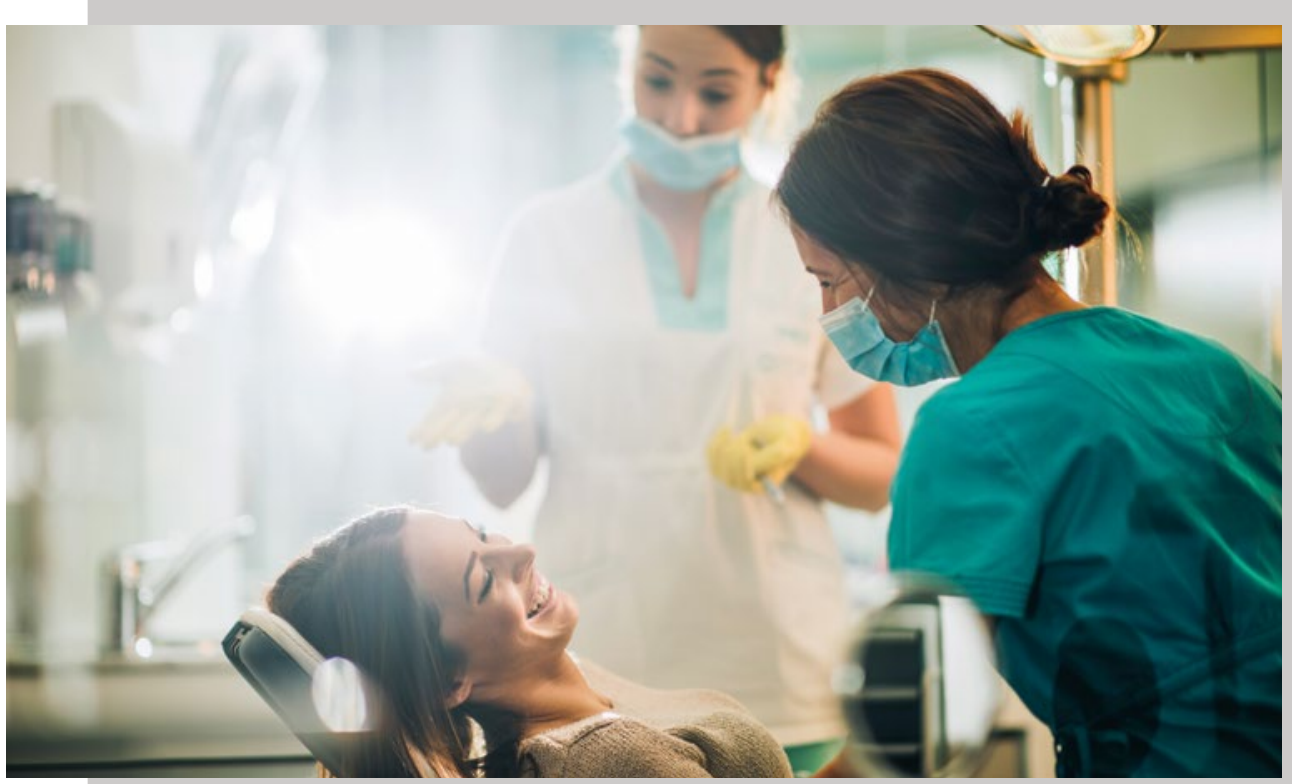

how to register. If you haven't yet had a chance to do so, we encourage you to login, review your details and update them as soon as you can.
If you haven't yet received your registration information, don't worry. It's possible that you're part of a group of dentists who do not yet have a unique email address on record, which is required so that you can be sent your individual registration information.

A unique email address is one that is used by a single individual. If your record contains an address that's not unique, and is linked to other dentists' records, you will not yet be able to use PCSE Online. An example of a non-unique email would be: info@organisation.com. An example of a unique email address, however, would be: john.smith@dentist.com.

At the moment you will not be able to change your registered email address, but PCSE is currently working on alternative ways to contact you to provide guidance, so that you can take advantage of the new service as soon as possible. 